\title{
Association of Urinary Albumin with HbA1c Levels in Subjects of Type 2 Diabetes Mellitus in Central India
}

\author{
Jayshri Sadashiv Jankar ${ }^{1}$, Kumud Namdeorao Harley², Kanchan Manoharrao Mohod ${ }^{3}$, Vijay Yashwantrao Babar ${ }^{4}$ \\ ${ }^{1}$ Department of Biochemistry, Jawaharlal Nehru Medical College, DMIMS, (Deemed to Be University) \\ Sawangi (Meghe), Wardha, Maharashtra, India. ${ }^{2}$ Department of Biochemistry, Government Medical College, \\ Akola, Maharashtra, India. ${ }^{3}$ Department of Biochemistry, Mahatma Gandhi Institute of Medical Sciences, \\ Sewagram, Wardha, Maharashtra, India. ${ }^{4}$ Department of Community Medicine, Jawaharlal Nehru Medical \\ College, DMIMS (Deemed to Be University) Sawangi, (Meghe), Wardha, Maharashtra, India
}

\section{ABSTRACT}

\section{BACKGROUND}

Diabetes mellitus is a long-lasting illness, frequently getting diagnosed when complications appear. Natural course of diabetic nephropathy can be seen with normoalbuminuria to microalbuminuria, then to chronic renal disease through overt proteinuria. Microalbuminuria is a renal marker of generalized vascular endothelial damage and early atherosclerosis. Patients having microalbuminuria are at higher risk of vascular complications of diabetes mellitus like myocardial infarction, cerebrovascular accident and diabetic nephropathy. Poor glycaemic control increases the risk of microalbuminuria. This is the reason why urinary albumin is used as a sensitive marker of diabetic nephropathy. The present study aimed to correlate the HbA1c levels with urinary albumin in subjects of type 2 diabetes mellitus.

\section{METHODS}

A cross sectional study was done at a tertiary care hospital. We studied 200 diagnosed subjects of type 2 diabetes mellitus. Depending on their urinary albumin excretion, they were categorized into 2 groups - groups 1 and 2. Group 1 and Group 2 subjects had a mean age of $43.75 \pm 5.95$ years and $51.06 \pm 7.94$ years respectively. Group 1 and 2 subjects had $7.06 \pm 0.56(\%)$ and $8.27 \pm 1.30(\%)$ of $\mathrm{HbA1c}$ respectively.

\section{RESULTS}

HbA1c levels were compared in Group $1(7.06 \pm 0.56)$ and Group $2(8.27 \pm 1.30)$ and the difference was statistically significant $(p$ value $=0.0001, S)$. We found positive correlation between urinary albumin and HbA1c in Groups $1(\mathrm{r}=0.255)$ and Group 2 $(\mathrm{r}=0.417)$.

\section{CONCLUSIONS}

Constant rise in glycated haemoglobin and micro albuminuria may be considered as risk factors in diabetic nephropathy. Therefore, regular screening for HbA1c and urinary albumin must be done as an early marker of renal dysfunction.

\author{
Corresponding Author: \\ Dr. Jayshri Sadashiv Jankar, \\ Assistant Professor, \\ Department of Biochemistry, \\ Jawaharlal Nehru Medical College, \\ DMIMS (Deemed to Be University), \\ Sawangi (Meghe), \\ Wardha - 442001, Maharashtra, India. \\ E-mail:jayshrijankar@gmail.com
}

DOI: $10.14260 /$ jemds/2020/859

How to Cite This Article: Jankar JS, Harley KN, Mohod KM, et al. Association of urinary albumin with $\mathrm{HbA1c}$ levels in subjects of type 2 diabetes mellitus in Central India. J Evolution Med Dent Sci 2020;9(52):3921-3925, DOI: 10.14260/jemds/2020/859

Submission 24-07-2020,

Peer Review 01-11-2020,

Acceptance 09-11-2020,

Published 28-12-2020.

Copyright (C) 2020 Jayshri Sadashiv Jankar et al. This is an open access article distributed under Creative Commons Attribution License [Attribution 4.0 International (CC BY 4.0)]

\section{KEY WORDS}

Urinary Albumin, HbA1c Levels, Type 2 Diabetes 


\section{BACKGROUND}

Type 2 Diabetes Mellitus (DM) is the most common cause of chronic renal disease with high prevalence. DM is an extensive health problem and lays a considerable load on health care services. The prevalence of diabetes for all age- groups worldwide was estimated to be $2.8 \%$ in 2000 and $4.4 \%$ in 2030. The total number of people with diabetes is estimated to increase from 171 million in 2000 to 366 million in 2030. The urban population in developing countries is projected to double between 2000 and $2030 .{ }^{1}$ The screening for DM type 2 is done either with a 2-hour oral glucose tolerance test or with HbA1c testing, as per recommended by the American Diabetes Association (ADA). ${ }^{2}$ Diabetic nephropathy is a secondary renal disease in patients with diabetes mellitus and is the common cause of renal morbidity in patients and have effect on around $40 \%$ diabetic patients. $^{3}$

The normal urinary protein excretion rate is $<150 \mathrm{mg} / 24$ hr. Albumin contributes to around $10 \%$ of total proteins excreted corresponding to an albumin excretion rate of $2-30$ $\mathrm{mg} / 24 \mathrm{hr}$. Microalbuminuria is defined as albumin excretion rates of $30-300 \mathrm{mg} / 24 \mathrm{hr}$. (called as incipient nephropathy). ${ }^{4}$ Microalbuminuria exhibits a considerable risk of developing renal disease than with less albumin excretion. ${ }^{5}$ Once aggressive nephropathy develops without specific interference, the Glomerular Filtration Rate (GFR) gradually declines over a period of several years at a rate which may differ from patient to patient $\left(2-20 \mathrm{ml} / \mathrm{min}\right.$ / year). ${ }^{6}$ Besides being the earlier manifestation of nephropathy, albuminuria is a greater marker for patients with both types diabetes mellitus with cardiovascular disease. ${ }^{7}$

Excessive protein glycosylation with the build-up of Advanced Glycosylated End-products (AGE's) results due to the binding of glucose to proteins, as a result which, there is increased in excretion of urinary albumin. This causes deposition of AGE's on the glomerulus causing thickening of glomerulus basement membrane, mesangial matrix accumulation, renal and glomerular hypertrophy. This abnormality allows the leaking of low molecular weight proteins (albumin). ${ }^{8}$ This is the stage of incipient nephropathy (microalbuminuria) which can be reversed with good glycaemic control. ${ }^{9}$ Reduction of $\mathrm{HbA} 1$ c level by $1 \%$ (i.e. $7.5 \%$ to $6.5 \%$ ) also grossly reduces microalbumin level, even to normal. ${ }^{10}$

Glycosylated haemoglobin indicates average plasma glucose over the period of 3 months. ${ }^{11}$ Quality of glycosylated haemoglobin of being tested at any time of the day without any special preparations, has made it the preferred test for assessment of glycaemic control in patients of diabetes mellitus. ${ }^{12}$ Likewise, estimating urinary albumin has become a gold standard for monitoring diabetic nephropathy progression. ${ }^{13}$

In the present study, we correlated association between urinary albumin excretion and HbA1c levels in subjects of type 2 diabetes mellitus.

\section{METHODS}

The study was started after obtaining clearance from the Institutional Human Ethical Committee.

\section{Subject Selection}

We included 200 diagnosed subjects of type 2 diabetes mellitus attending Outpatient Department of a rural medical college in central India. The sample size was based on purposive sampling method. Patients with fasting blood sugar level $>126 \mathrm{mg} / \mathrm{dL}$ and post meal blood sugar $>200 \mathrm{mg} / \mathrm{dL}$ were included and patients with history of hypertension, obesity, renal diseases, liver disease, valvular heart diseases, smoking, family history of diabetes and any infection were excluded.

\section{Sample Collection}

Sample was collected after obtaining written / informed consent in regional language from subject or subject's legal representative, attending a tertiary level rural hospital.

- Urine Sample - $24 \mathrm{hr}$. urine sample was collected for estimation of albumin in urine

- Blood Sample - $2 \mathrm{ml}$ of blood sample was collected from antecubital vein and stored in EDTA (Ethylene-DiamineTetra-Acetic Acid) bulb. The samples were allowed to clot $\&$ then be centrifuged at $3000 \mathrm{rpm}$ for at least 10 minutes to separate plasma. After separating plasma, buffy coat was removed, and the remaining erythrocytes were used to prepare the haemolysate. The haemolysate was stored at $-20^{\circ} \mathrm{C}$ in aliquots and used for was estimation of glycosylated haemoglobin.

\section{Single Radial Immuno Diffusion for Estimation of Microalbuminuria14}

\section{Principle}

In agarose gel containing mono specific antiserum at a dilution appropriate for the range of antigen concentration desired, wells are cut in the gel into which a standard volume of antigen solution is placed, which diffuses into the surrounding gel. The antigen antibody complex is revealed as a ring of precipitate. At equilibrium, the antigen concentration is proportional to the square of the diameter of the ring.

\section{Reagents}

- $\quad$ Agarose (Sigma 2790) gel (1\%): One gm low endosmosis agarose dissolved in $100 \mathrm{ml}$ hot barbital buffer.

- Antihuman serum albumin antibody.

- Albumin standards: $0.5 \mathrm{mg} / \mathrm{dL}, 1 \mathrm{mg} / \mathrm{dL}, 2 \mathrm{mg} / \mathrm{dL}, 4$ $\mathrm{mg} / \mathrm{dL}, 8 \mathrm{mg} / \mathrm{dL}$, of HSA in 0.05M. Phosphate buffer.

- Coomassie blue stain (Sisco 024018,): In 1 litre of staining solution, containing water, acetic acid, and methanol in the proportion of 5:1:5, Coomassie brilliant blue R (5 gm) was dissolved.

\section{Procedure}

Monospecific human serum antibody $150 \mu \mathrm{L}$ (as standardized by trial-and-error method) was incorporated into $15 \mathrm{ml}$ of molten agarose gel (1\%) at $560 \mathrm{C}$ taken in small glass beaker and mixed thoroughly by gentle rotation. The agarose gel was poured onto the glass slide of $12.5 \times 7.5 \mathrm{~cm}$ size. It was allowed to solidify for half an hour at $40 \mathrm{C}$ in a humid chamber. Wells were punched out at $1.5 \mathrm{~cm}$ apart each other using the gel cutter and the water suction pump. The individual well was charged with $5 \mu \mathrm{L}$ of the urine / standard with micropipette. 
The loaded gel was allowed to diffuse for $24 \mathrm{hrs}$. at $40 \mathrm{C}$ in a moist chamber. The resulting ring diameters of the circular immunoprecipitates were noted. Damp filter paper was kept over the slide for drying at room temperature. The dried plate was put into Coomassie brilliant blue R stain for 30 minutes. Then washed under the tap and destained with destaining solution till background was clear. Standard curve was plotted taking the square of the diameter on y axis against the concentration of standards on $\mathrm{x}$ axis. The concentration of the unknown samples was read from the graph by measuring diameters of the rings.

\section{Estimation of Glycosylated Haemoglobin 15}

As the amount of HbA1c also depends on total quality of haemoglobin the reported $\mathrm{HbA1c}$ value is indicated as a percentage of the total haemoglobin concentration.

\section{Principle}

Total $\mathrm{Hb}$ and $\mathrm{HbA1c}$ in haemolyzed blood bind with the same affinity to particles in R1. The amount of binding is proportional to the relative concentration of both substances in the blood. Mouse anti-human HbA1c monoclonal antibody (R2a) binds to particle bound HbA1c. Goat anti-mouse IgG polyclonal antibody (R2b) interacts with the monoclonal mouse anti-human HbA1c antibody and agglutination takes place. The measured absorbance is proportional to the HbA1c bound to particles, which in turn is proportional to the percentage of $\mathrm{HbA} 1 \mathrm{c}$ in the sample.

\section{Lysis of Blood Sample}

It was done by adding $500 \mu \mathrm{L}$ of R3 to $10 \mu \mathrm{L}$ of EDTA blood sample. This solution was mixed well and then kept at room temperature for 10 minutes.

\begin{tabular}{|c|c|}
\hline \multicolumn{2}{|l|}{ R1 } \\
\hline Buffer & $20 \mathrm{mmol} / \mathrm{L}$ \\
\hline Latex & $1.5 \%$ \\
\hline \multicolumn{2}{|l|}{ R2a } \\
\hline Buffer & $10 \mathrm{mmol} / \mathrm{L}$ \\
\hline $\begin{array}{l}\text { Mouse Anti-Human HbA1c Monoclonal } \\
\text { Antibody }\end{array}$ & $5.5 \mathrm{mg} / \mathrm{dL}$ \\
\hline \multicolumn{2}{|l|}{ R2b } \\
\hline Buffer & $1 \mathrm{mmol} / \mathrm{L}$ \\
\hline $\begin{array}{l}\text { Goat Anti-Mouse IgG Polyclonal Antibody } \\
\text { Stabilizers }\end{array}$ & $67 \mathrm{mg} / \mathrm{dL}$ \\
\hline R3. Haemolysing & \\
\hline
\end{tabular}

Preparation of $\mathrm{R} 2$ Working Reagent

It was done by adding R2a 2 parts to R2b 1 part.

Assay Procedure

Reagents were pipetted into $2 \mathrm{ml}$ glass vials labelled as "Blank", "Standard" and "Test" as following per protocol.

\begin{tabular}{|cccc|}
\hline Tube / Reagent & Blank & Standard & Test \\
Reagent R1 & $140 \mu \mathrm{L}$ & $140 \mu \mathrm{L}$ & $140 \mu \mathrm{L}$ \\
Sample & -- & -- & $3.6 \mu \mathrm{L}$ \\
Standard & -- & $3.6 \mu \mathrm{L}$ & -- \\
Working Reagent R2 & $\mathbf{7 0} \mu \mathrm{L}$ & $\mathbf{7 0} \boldsymbol{\mu L}$ & $\mathbf{7 0} \boldsymbol{\mu L}$ \\
\hline (2 - Part R2a + 1 - Part R2b) & &
\end{tabular}

The contents were mixed well \& incubated for $10 \mathrm{~min}$ at $37^{\circ} \mathrm{C}$. The absorbance of standard and each sample tube was measured against reagent blank at $660 \mathrm{~nm}$.
Calculation

$\operatorname{HbA1c}(\%)=$

Absorbance of sample $\times$ conc. of standard mmol / mol)

Absorbance of standard

\section{Statistical Analysis}

The biochemical analysis was carried out at our Central Clinical Biochemistry Laboratory. The samples were analysed by Erba EM 360 (Random Access Analyser). Data were analysed using descriptive and inferential statistics using student unpaired t-test and software used were SPSS version 24.0 and GraphPad prism 7.0 version. $\mathrm{P}<0.05$ is considered as level of significance. Pearson correlation coefficient was used to find the linear relation between $\mathrm{HbA} 1 \mathrm{c}$ and urinary albumin. All values were expressed as Mean \pm SD. P value was obtained using students unpaired t test.

\section{RESULTS}

This hospital based cross sectional study was done at a tertiary care hospital. In this present study, subjects with Type 2 Diabetes Mellitus (T2DM) disease with duration more than one year and age 30 years and above. Subjects were divided into two groups. Group 1 includes 123 Type 2 DM subjects with normoalbuminuria (i.e., with Urine Albumin $<20$ mg / 24 hr). Group 2 includes 77 Type 2 DM subjects with microalbuminuria (i.e., with Urine Albumin $>20$ to $<300 \mathrm{mg}$ / $24 \mathrm{hr}$ ).

\section{Gender and Age Wise Distribution}

Distribution of total subjects according to their gender and age was shown in table 5.2 and graph 5.2 (a) and 5.2 (b). Group 1 had 123 subjects (Male $=70$ and Female $=53$ ). Group 2 had total 77 subjects (Male $=50$ and Female $=53$ ) The male and female ratio was not of much significance in both groups. However, age in years shows significant change in both groups with mean \pm SD of $43.75 \pm 5.95$ in group 1 and $51.06 \pm 7.94$ in group 2 .

\begin{tabular}{|cccc|}
\hline Gender & Group 1 (n= 123) & Group 2 (n= 77) & P-Value \\
Male & $70(56.91 \%)$ & $50(64.94 \%)$ & $0.24, \mathrm{p}>0.05 \mathrm{NS}$ \\
Female & $53(43.09 \%)$ & $27(35.06 \%)$ & \\
& Average Age wise Distribution \\
Age (years) & $\begin{array}{c}43.75 \pm 5.95 \\
\text { (Range }=34-62 \text { yrs) }\end{array}$ & $\begin{array}{c}51.06 \pm 7.94 \\
\text { (Range }=34-64 \text { yrs.) }\end{array}$ \\
\hline \multicolumn{5}{|c}{ Table 1. Gender and Age Wise Distribution } \\
\hline $\mathrm{p}>0.05=$ Non-Significant $(\mathrm{NS}), \mathrm{p}<0.05=$ Significant $(\mathrm{S}) ; \mathrm{n}=$ Number \\
\hline
\end{tabular}

\section{Estimation of HbA1c Levels in Both Groups}

Glycosylated haemoglobin (HbA1c) showed significantly higher levels in group 2 subjects as compared to group 1 as seen in table No. 2.

\begin{tabular}{|cccc|}
\hline Parameter & Group 1 & Group 2 & P-Value \\
HbA1c (\%) & $7.06 \pm 0.56$ & $8.27 \pm 1.30$ & $0.0001, \mathrm{~S}$ \\
\hline \multicolumn{4}{|c|}{ Table 2. Comparison of HbA1c Levels in Group 1 \& Group 2 Subjects } \\
\hline $\mathrm{p}<0.05$ = Significant $(\mathrm{S})$ \\
\hline
\end{tabular}


Correlation of Urinary Albumin with HbA1c Levels Studied in Group 1 and Group 2 Subjects

\begin{tabular}{|c|c|c|c|c|}
\hline Variables & Mean & SD & Correlation 'r' & P-Value \\
\hline Urinary Albumin (mg / 24 hr.) & 14.68 & 6.63 & & \\
\hline $\operatorname{HbA1c}(\%)$ & 7.05 & 0.55 & 0.255 & $0.004, \mathrm{~S}$ \\
\hline \multicolumn{5}{|c|}{$\mathrm{p}<0.05=$ Significant $(\mathrm{S})$} \\
\hline \multicolumn{5}{|c|}{ 3A. Correlation of Urinary Albumin with HbA1c Levels in Group 1} \\
\hline Var & Mean & SD & Correlatic & P-Value \\
\hline Urinary Albumin (mg / 24 hr.) & 60.76 & 18.73 & - & - \\
\hline HbA1c (\%) & 8.27 & 1.29 & 0.417 & $0.0001, \mathrm{~S}$ \\
\hline \multicolumn{5}{|c|}{$\mathrm{p}<0.05=$ Significant $(\mathrm{S})$} \\
\hline \multicolumn{5}{|c|}{ 3B. Correlation of Urinary Albumin with HbA1c Levels in Group 2} \\
\hline & Table & & & \\
\hline
\end{tabular}

Table 3A depicts Pearson's correlation of HbA1c levels in group 1 with urinary albumin. It was found that there is linear correlation between urinary albumin and HbA1c levels in group $1(r=0.255$, $p$ value $=0.004)$

Table 3B depicts Pearson's correlation of HbA1c levels in group 2 with urinary albumin. It was found that there is linear correlation between urinary albumin and $\mathrm{HbA1c}$ levels in group $2(r=0.417, p$ value $=0.0001)$.

\section{DISCUSSION}

We enrolled a total 200 diagnosed subjects of type 2 diabetes mellitus with average age of $43.75 \pm 5.95$ years in group $1(\mathrm{n}=$ $123)$ and $51.06 \pm 7.94$ years in group $2(n=77)$. Most of the subjects were clustered between 30 to 55 years of age. Other studies done in developing countries have found that majority of patients with diabetes are in the age group of 45 - 64 years, whereas in developed countries, diabetes mellitus is diagnosed at higher age ( $>65$ years).1,16 Beginning of diabetes mellitus at lower age hints that these patients may develop diabetes in the high yielding years of their life and have a higher chance of starting complications. The prevalence of diabetes in the young Indian people may be explained by both environmental and genetic factors. ${ }^{17}$

Different ways of estimating microalbuminuria, racial differences in the study populations, method of urine collection may be credited for the differences in prevalence of albuminuria.

In our study, we found that the mean age of the patients with normoalbuminuria ( $43.75 \pm 5.95$ years) was significantly lower than microalbuminuria patients $(51.06 \pm 7.94$ years $)$. This showed that prevalence of microalbuminuria rises as the age increases. Similar studies from India shows that the mean age of patients with normoalbuminuria is lower as compared to mean age of patients with microalbuminuria. ${ }^{18,19}$

We found that there is positive correlation of urine albumin with HbA1c levels in both group $1(\mathrm{r}=0.255$; $\mathrm{p}$ value $=0.004)$ and group 2 ( $r=0.0001$; p value $=)$. Our study is consistent with other researchers proving support for complete screening for diabetic complications especially microalbuminuria at the time of diagnosis of type 2 diabetes mellitus. Increased albumin excretion and other microvascular complications take place with substantial frequency before diabetes is diagnosed clinically. The correlation between the development of microalbuminuria and degree of hyperglycaemia shows that early action towards obtaining glycaemic control might serve to help prevent the development of diabetic nephropathy. ${ }^{20,21}$

\section{CONCLUSIONS}

It was concluded that in a developing country like India, there is a need of microalbuminuria and $\mathrm{HbA} 1 \mathrm{c}$ testing in both newly diagnosed as well as already diagnosed type 2 diabetic patients as an early marker of renal risk factor. The present study emphasizes on education about strict glycaemic control and testing for microalbuminuria, which is an early indicator of diabetic nephropathy, and should be mandatory for all type 2 diabetes patients.

Data sharing statement provided by the authors is available with the full text of this article at jemds.com.

Financial or other competing interests: None.

Disclosure forms provided by the authors are available with the full text of this article at jemds.com.

\section{REFERENCES}

[1] Wild S, Roglic G, Green A, et al. Global prevalence of diabetes: estimates for the year 2000 and projections for 2030. Diabetes Care 2004;27(5):1047-53.

[2] Alam U, Asghar O, Azmi S, et al. General aspects of diabetes mellitus. Handb Clin Neurol 2014;126:211-22.

[3] United States Renal Data Systems: Annual Data Report. Atlas of end stage renal disease in the US. Bethseda: National Institute of Health: National Institute of Diabetes and Digestive and Kidney Disease 2003.

[4] Kashif W, Siddiqi N, Dincer AP, et al. Proteinuria: how to evaluate an important finding. Cleve Clin J Med 2003;70(6):535-47.

[5] Mayne PD. Nephropathy. In: Clinical chemistry in diagnosis and treatment. $6^{\text {th }}$ edn. ELST Print 2001: p. 3312.

[6] Mongensen CE, Keane WF, Bennett PH, et al. Prevention of diabetic renal disease with special reference to microalbuminuria. Lancet 1995;346(8982):1080-4.

[7] Valmadrid CT, Klein R, Moss SE, et al. The risk of cardiovascular disease mortality associated with microalbuminuria and gross proteinuria in persons with older - onset diabetes mellitus. Arch Intern Med 2000;160(8):1093-103.

[8] Mason RM, Wahab NA. Extracellular matrix metabolism in diabetic nephropathy. J Am Soc Nephrol 2003;14(5):1358-73.

[9] Vergouwe Y, Soedamah-Muthu SS, Zgibor J, et al. Progression to microalbuminuria in type 1 diabetes: development and validation of a prediction rule. Diabetologia 2010;53(2):254-62.

[10] Tobe SW, McFarlane PA, Naimark DM. Microalbuminuria in diabetes mellitus. CMAJ 2002;167(5):499-503.

[11] Wild SH, Roglic G, Sicree R, et al. Global Burden of diabetes mellitus in the Year 2000. http://www3.who. int/whosis/menu.cfm?path=evidence,burden,burdengbd 2000 docs. 
[12] Dulal RK, Karki S. Disease management programme for diabetes mellitus in Nepal. J Nepal Med Assoc 2009;48(176):281-6.

[13] World Health Organization 2014 http://www.worldlifeexpectancy.com/nepal-diabetesmellitus

[14] Mancini G, Carbonara AO, Heremans JF. Immunochemical quantitation of antigens by single radial immunodiffusion 1965;2(5):234-54.

[15] Myers GL, Miller GW, Coresh J, et al. Recommendations for improving serum creatinine measurement. Clin Chem 2006;52(1):5-18.

[16] Ramachandran A. Socio - economic burden of diabetes in India. J Assoc Physicians India 2007;(Suppl 55):9-12.

[17] Mohan V, Deepa R. Adipocytokines and the expanding Asian Indian Phenotype. J Assoc Physicians India 2006;54:685-6.
[18] Thakkar B, Arora K, Vekariya R, et al. Prevalence of microalbuminuria in newly diagnosed type 2 diabetes mellitus. Natl J Integr Res Med 2011;2:22-5.

[19] Agarwal N, Sengar NS, Jain PK, et al. Nephropathy in newly diagnosed type 2 diabetics with special stress on the role of hypertension. J Assoc Physicians India 2011;59:145-7.

[20] Mir SR, Bhat MH, Misgar RA, et al. Prevalence of microalbuminuria in newly diagnosed $\mathrm{t} 2 \mathrm{dm}$ patients attending a tertiary care hospital in north india and its association with various risk factors. International Journal of Contemporary Medical Research 2019;6(4):D9-11.

[21] Muraliswaran P, Aparna G, Kanagavalli P, et al. Association between microalbuminuria and $\mathrm{HbA1C}$ among known type 2 diabetic patients in Puducherry population - a comparative study. IOSR Journal of Biotechnology and Biochemistry 2016;2(6):15-7. 